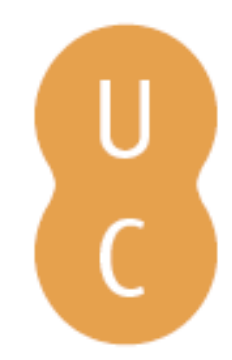

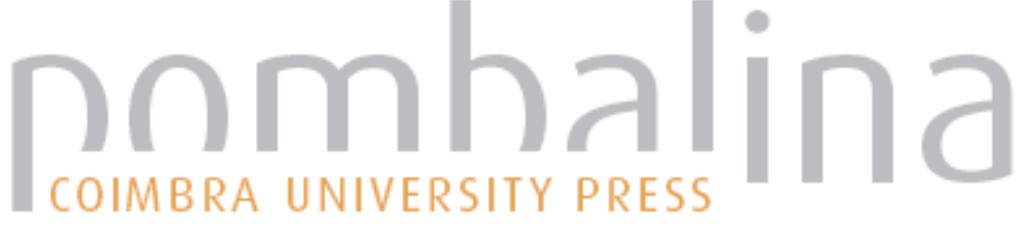

\section{Investigação científica para quem?}
Autor(es):
Hildyard, Nicholas
Publicado por: Imprensa da Universidade de Coimbra; Gradiva
URL
persistente:
URI:http://hdl.handle.net/10316.2/32708
DOI:
DOI:http://dx.doi.org/10.14195/978-989-26-0389-6_21

Accessed : $\quad$ 26-Apr-2023 08:25:33

A navegação consulta e descarregamento dos títulos inseridos nas Bibliotecas Digitais UC Digitalis, UC Pombalina e UC Impactum, pressupõem a aceitação plena e sem reservas dos Termos e Condições de Uso destas Bibliotecas Digitais, disponíveis em https://digitalis.uc.pt/pt-pt/termos.

Conforme exposto nos referidos Termos e Condições de Uso, o descarregamento de títulos de acesso restrito requer uma licença válida de autorização devendo o utilizador aceder ao(s) documento(s) a partir de um endereço de IP da instituição detentora da supramencionada licença.

Ao utilizador é apenas permitido o descarregamento para uso pessoal, pelo que o emprego do(s) título(s) descarregado(s) para outro fim, designadamente comercial, carece de autorização do respetivo autor ou editor da obra.

Na medida em que todas as obras da UC Digitalis se encontram protegidas pelo Código do Direito de Autor e Direitos Conexos e demais legislação aplicável, toda a cópia, parcial ou total, deste documento, nos casos em que é legalmente admitida, deverá conter ou fazer-se acompanhar por este aviso.

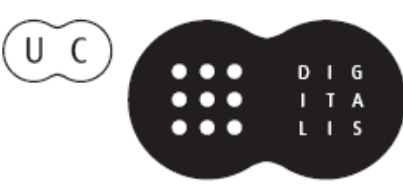


C I E N C I A I B E R T A

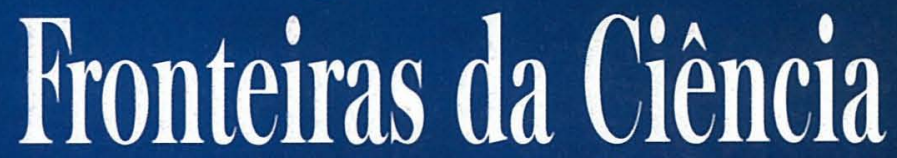

Desenvolvimentos Recentes - Desafios Futuros

RUI FAUSTO • CARLOS FIOLHAIS • JOÃO FILPE QUURRÓ

Coordenadores

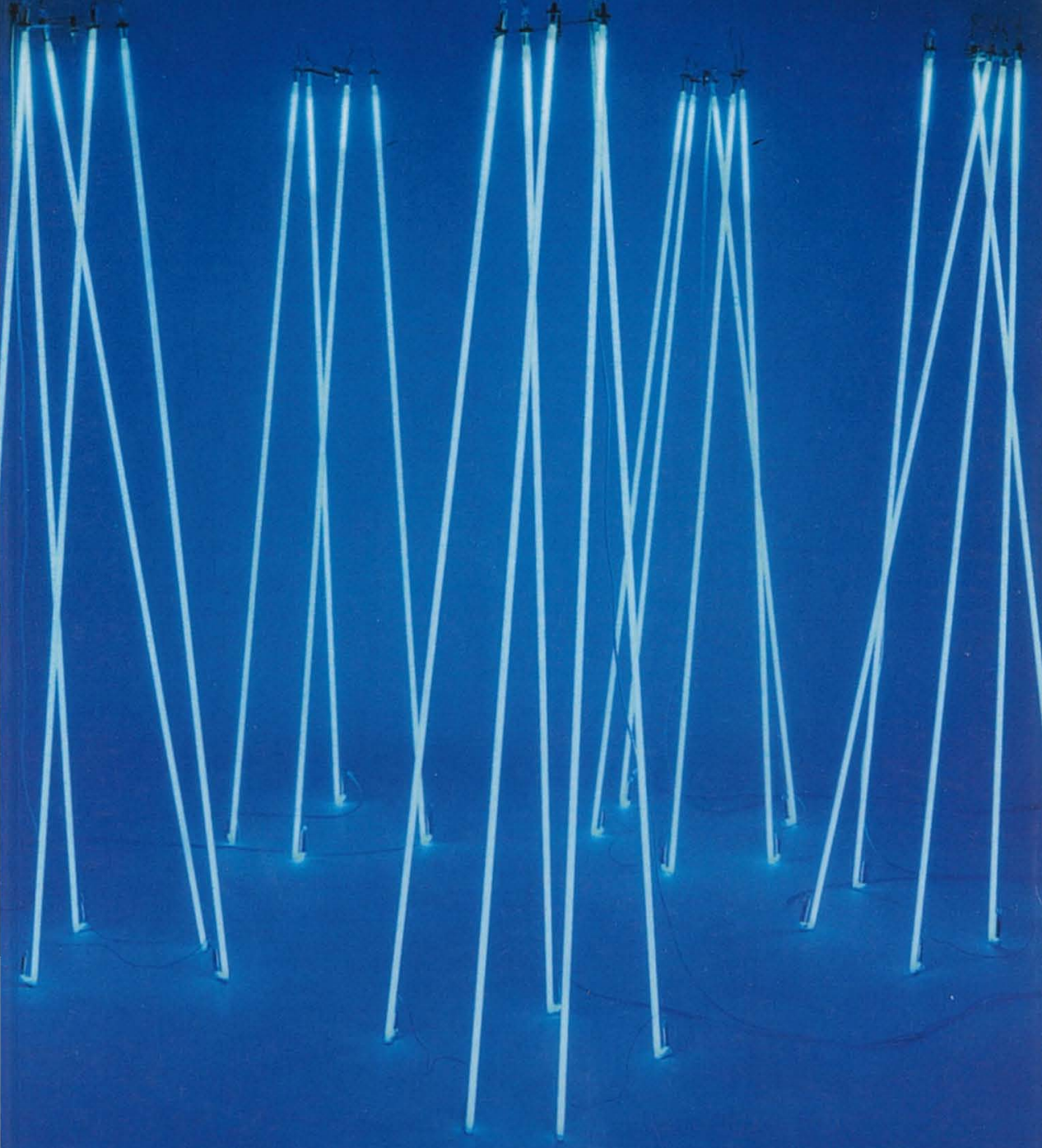

gradiva - Imprensa da Universidade de Coimbra 
(Página deixada propositadamente em branco) 


\section{RUI FAUSTO, CARLOS FIOLHAIS JOÃO FILIPE QUEIRÓ \\ Coordenadores}
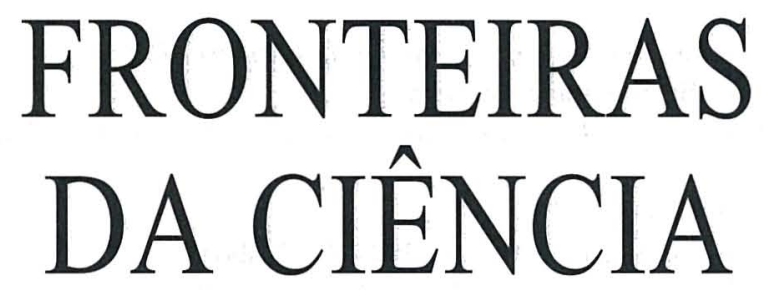

Desenvolvimentos Recentes Desafios Futuros 
(C) Gradiva - Publicações, L. da / Imprensa da Universidade de Coimbra, 2003 Coordenação editorial: Rui Fausto, Carlos Fiolhais e João Filipe Queiró Tradução: Jean Burrows, Vivien Burrows, Rui Fausto, Carlos Fiolhais e João Filipe Queiró

Revisão do texto: Isabel Pedrome

Capa: António Barros [Imprensa da Universidade. Coimbra], sobre imagem de «Águas Vivas», escultura de Silvestre Pestana, 2001

Foto: António Alves; Infografia: ESTÍMULUS [design]; Cortesia: Galeria Alvarez-Arte Contemporânea

Paginação: António Resende e Paula Isabel Jorge

Impressão e acabamento: G.C. - Gráfica de Coimbra, L. ${ }^{d a}$

Reservados os direitos para Portugal por:

Gradiva - Publicações, L. ${ }^{\text {da }}$ e Imprensa da Universidade de Coimbra

Gradiva - Publicações, L.da

Rua Almeida e Sousa, 21, r/c, esq.•1399-041 Lisboa

Telefs. $213974067 / 8 \cdot 213971357 \cdot 213953470$

Fax $213953471 \cdot$ Email: gradiva@ip.pt

URL: http://www.gradiva.pt

Imprensa da Universidade de Coimbra

Rua Antero de Quental, 195 • 3000-033 Coimbra

Telefs. 351239853110

Fax 3512398531 19・e-mail: fjrpress@ci.uc.pt

URL: http://www.imp.uc.pt

ISBN: 972-662-923-3

1." edição: Agosto de 2003

Depósito legal n. ${ }^{\circ} 199$ 463/2003 
Nicholas Hildyard

The Corner House

Dorset

Reino Unido

\section{Investigação científica para quem?}

Queria falar-vos da política da vida quotidiana e dos seus efeitos no laboratório científico. Queria falar-vos sobre o modo como o financiamento da ciência afecta a visão do mundo que a ciência transmite e de como as pressões económicas e sociais da vida quotidiana - a hipoteca, as noites mal dormidas por causa do bebé - afectam a direcção e os resultados da investigação científica. E quero defender uma ciência em que os cientistas não só sejam mais abertos às forças políticas que determinam os seus programas de investigação, como também se empenhem activamente em tornar essas forças políticas mais responsáveis perante o público, em denunciar orientações regressivas e em fazer pressão por uma ciência que sirva o interesse público, por oposição a interesses de elite.

Vou começar com um pouco de matemática. Eis uma pergunta: estão a cozinhar uma empada; se demoram um minuto a picar as cebolas, um minuto a cortar as cenouras, um minuto a descascar as batatas e vinte minutos a cozê-la no forno, quanto tempo demoram a fazer a empada?

Vinte e três minutos, não é? Bom, está certo e está errado. Estudos de sociólogos sugerem que a resolução de problemas de todos os dias está longe de ser incontroversa (J. Lave, 1996, L. Nader, 1996, J. Gay e M. Cole, 1967). Como observa Jean Lave, as pessoas adaptam o seu raciocínio matemático quando passam de um contexto prático para outro (J. Lave, 1996). Para muitas pessoas, por exemplo, está longe de ser óbvio que a empada demorará 23 minutos a fazer. E os 20 minutos necessários para 
aquecer o forno? Ou os 3 minutos para lavar as facas e a tábua de cortar os legumes?

Está bem, está bem. Isso é um disparate, dizem-me. Não se pode esperar que entremos em conta com isso. A pergunta não era essa. Isso é batota. Pois bem, não penso que seja. Com aqueles pressupostos, uma resposta de 23 minutos dá uma imagem do mundo que não parece verdadeira.

Uso este exemplo para tirar uma conclusão simples: mesmo a matemática - supostamente a ciência mais livre de valores - está cheia de pressupostos implícitos. Toda a análise — por mais simples que seja tem lugar dentro de um contexto cultural e é atravessada por pressupostos culturais. E a análise científica, apesar das afirmações em contrário, não é excepção. Como afirma a socióloga e crítica feminista Sandra Harding:

Muitos estudos recentes em todas as áreas da sociologia das ciências forçam-nos a reconhecer que todo o conhecimento cientifico é sempre, em todos os aspectos, socialmente situado. Nem os conhecedores nem o conhecimento que eles produzem são ou podem ser imparciais, desinteressados, neutros, arquimedianos. (S. Harding, 1991:13)

E continua:

A natureza inanimada chega-nos sempre culturalmente pré-construida como um possivel objecto de conhecimento, tal como os seres humanos. Os seres humanos constroem-se a si próprios como possíveis objectos de conhecimento e também construíram a natureza inanimada como possivel objecto de conhecimento. Não podemos «despir a natureza», para "revelar os seus segredos», como sustentaram as visões convencionais do mundo, porque, por mais que o striptease continue ou por mais rigorosa que seja a sua coreografia, encontraremos sempre, por baixo de cada «véu», a natureza conceptualizada em projectos culturais: encontraremos sempre mais véus (mas não só). Além disso, acontece que a própria tentativa de despir a natureza tece mais véus. A natureza como objecto de conhecimento estimula a cultura, e a ciência é parte da actividade cultural que produz continuamente a «natureza como objecto de conhecimento» em formas culturalmente especificas.

Para grupos subalternizados e oprimidos - as mulheres e as minorias étnicas, por exemplo - a influência de pressupostos culturais na determinação de programas de investigação científica e no condicionamento da análise científica é óbvia há muito tempo.

Vou dar dois exemplos, o primeiro tirado de um estudo de investigações sobre riscos ligados à reprodução pela minha colega na Corner House Sarah Sexton. Ela observa que muitas das primeiras investigações sobre riscos ligados à reprodução no local de trabalho - juntamente com as 
respostas empresariais e legislativas à confirmação desses riscos estavam condicionadas por pressupostos ideológicos sobre a reprodução humana e as mulheres no trabalho.

O primeiro e mais óbvio desses pressupostos era que a reprodução é uma questão das mulheres - e só das mulheres. Em resultado deste pressuposto, diz Sexton, os efeitos de produtos químicos têm sido habitualmente avaliados considerando se a exposição da mãe durante a gravidez aumenta os riscos de defeitos da criança ao nascer. A sequência dos efeitos é tomada apenas através da mulher; o tempo crítico é considerado apenas o periodo da gravidez e os defeitos ao nascer são vistos como o único efeito negativo relevante a estudar. (S. Sexton, 1993)

Ao não ver a reprodução humana como um continuum mais vasto em que os homens desempenham um papel tal como as mulheres, os riscos que os produtos químicos criam para a saúde dos homens do ponto de vista da reprodução e para o feto através dos homens têm sido repetidamente ignorados. Uma visão parcial, sexista e culturalmente determinada da reprodução resultou numa agenda de investigação em que os homens, até há pouco, têm sido praticamente invisíveis. No entanto, a raridade das investigações sobre a exposição paterna e a ausência de legislação que proteja a saúde dos homens não significam que eles sejam imunes a riscos deste tipo. Longe disso; como sabemos hoje, os homens expostos a produtos químicos contendo estrogéneos - tanto na alimentação como no local de trabalho - estão a exibir baixos números de espermatozóides; sabemos hoje que os homens expostos a radiações no local de trabalho fazem os seus filhos correr o risco de contrair leucemia nos primeiros anos de vida. Além disso sabemos hoje que os filhos de homens expostos a DBCP (dibromocloropropano) e a um conjunto de outros factores de risco têm maiores taxas de defeitos ao nascer.

Aqui está portanto um exemplo de investigação científica distorcida, de forma subtil mas decisiva, por pressupostos culturais - neste caso o pressuposto de a reprodução ser «assunto de mulheres».

Outro exemplo em que pressupostos ideológicos não expressos condicionam a investigação científica vem da área dos contraceptivos. Judith Richter, uma investigadora alemã, tem vindo a seguir de perto a investigação do desenvolvimento de vacinas antifertilidade, que têm como objectivo induzir o sistema imunitário do corpo humano a gerar uma resposta imunitária temporária contra as células ou moléculas essenciais à reprodução - a saber, as hormonas que desencadeiam o amadurecimento e a libertação mensais de óvulos na mulher ou a produção contínua de esperma no homem, os próprios óvulos ou esperma ou as hormonas relacionadas com a gravidez. 
Acontece que vários ensaios mostraram que estes contraceptivos são inseguros e em larga medida ineficazes. $\mathrm{Na}$ verdade, do ponto de vista do utente individual são um desastre e apresentam riscos elevados.

A investigação, no entanto, continua. Porquê? A resposta, sustenta Richter, é que o quadro de referência "populacional» em que a investigação se realiza - e que determina a sua direcção - não está muito preocupado com a segurança ou os riscos dos contraceptivos do ponto de vista dos utentes individuais, sendo antes motivado pela procura de um método fiável de controlo de massas populacionais. Richter cita um imunologista australiano: as vacinas de regulação da fertilidade proporcionam a forma mais prática de controlar as taxas de nascimentos, em particular nos paises subdesenvolvidos. (J. Richter, 1996)

Comenta Richter: Um quadro conceptual de referência a que subjaz uma preocupação com a "sobrepopulação» não implica que quem se dedica à investigação em contraceptivos e ao planeamento familiar queira ignorar a saúde e o bem-estar das pessoas... Mas enquanto os imuno contraceptivos forem vistos como «vacinas» contra epidemias de gravidez ou como "armas antigénicas» no "arsenal do planeamento familiar», é provável que o bem-estar dos individuos que usam os contraceptivos fique em segundo plano.

O quadro de referência em que os contraceptivos estão a ser desenvolvidos - um quadro de referência que vê a gravidez como uma doença e o controlo populacional como uma prioridade máxima conduziu a uma tecnologia de controlo da natalidade que está sujeita a abusos grosseiros, até porque está pensada para uma utilização em massa. Se o quadro de referência fosse baseado em pressupostos ideológicos e políticos diferentes, ter-se-ia um programa de investigação - e um resultado - muito diferente. Em vez de se realçar o controlo dos nascimentos, por exemplo, poderia ter-se dado ênfase à integridade, dignidade e bem-estar dos utentes individuais - ao maior controlo de cada um do seu próprio comportamento reprodutivo.

Muitos cientistas reconhecem que a investigação científica pode ser mal aplicada, mas atribuem toda a culpa aos políticos ou às empresas que aplicam a sua investigação supostamente pura de forma socialmente irresponsável (S. Harding, 1991:2). Aceitam que podem aparecer frankensteins, mas não olham para a maneira como eles foram criados. Como diz Sandra Harding: A maneira como o monstro na verdade foi criado - e se alimenta e reproduz dia após dia - desaparece na sombra, como se não houvesse pessoas e práticas institucionais que possam ser responsabilizadas pela condição das ciências e pelo tipo de ordem social a que elas se têm associado. (S. Harding, 1991:2-3) 
A ironia está em que enquanto os cientistas não familiarizados com os mecanismos do poder continuam a insistir numa separação entre investigação «pura» e «aplicada», os políticos e os industriais nunca fizeram uma tal confusão.

Eles estão bem conscientes de quão estreita é — se é que ela existe a linha divisória entre as chamadas investigação «pura» e «aplicada». Recordem-se, por exemplo, os extraordinários esforços do governo norte-americano para garantir que eram os Estados Unidos - e não a Rússia - a apoderar-se dos numerosos cientistas «puros» que trabalhavam no programa de foguetões do regime nazi. Até se resolveu ignorar o envolvimento de muitos destes cientistas nas experiências mais monstruosas em prisioneiros de campos de concentração, proporcionando-lhes novas identidades no quadro de um projecto secreto cujo nome de código era Projecto Clip.

A indústria também conhece o valor de garantir que a investigação pura tenha fortes ligações às empresas - e que ela seja capturada e controlada antes de se tornar um trunfo para os rivais.

Há boas razões para isto. Consigo lembrar-me pelo menos de quatro:

- Em primeiro lugar, o controlo da investigação, primariamente através do financiamento, dá à indústria um controlo efectivo sobre os seus resultados.

Cito apenas um exemplo, dado pelo falecido Robert van den Bosch, um distinto entomologista que estava tão alarmado com a influência do financiamento das empresas na fiabilidade da investigação sobre pesticidas que publicou um livro pioneiro, A Conspiração dos Pesticidas (R. van den Bosch, 1980).

Van den Bosch era um crítico declarado daquilo a que chamava $a$ máfia dos pesticidas - o poderoso grupo de interesses que mantêm a moderna agricultura «viciada» no uso de pesticidas. A arma mais poderosa desta máfia é o dinheiro e ela usa-a de forma implacável. Manipulando o sistema de subsídios às universidades onde se realiza a investigação sobre controlo de pragas, a indústria de pesticidas garante que muitos investigadores estão de facto no seu bolso e receiam sair da linha com medo de perderem o seu financiamento. Os individualistas que recusam afeiçoar os resultados da sua investigação aos ditames da indústria são frequentemente perseguidos, intimidados e mesmo ameaçados.

Um caso típico citado por van den Bosch é o de um jovem investigador da Universidade da Califórnia que descobriu amostras comerciais de tomate enlatado que tinha sido fortemente pulverizado que continham tantos insectos como outras que não tinham recebido pesticidas. Decidiu 
escrever isto num artigo. No entanto, os conserveiros de tomate souberam e mandaram uma delegação aos administradores da universidade a queixar-se do manuscrito e ameaçando retirar subsídios se ele fosse publicado. A hierarquia da universidade, preocupada com essa possibilidade, sugeriu ao investigador que recuasse. A descrição da sua reacção reflecte a realidade da vida em muitos laboratórios de investigação. Como ele disse a Van den Bosch: Que diabo, Van, o que é que eu podia fazer? Eu não era mais do que um tipo insignificante que sustentava uma família e estava à espera de ser promovido. Pode ter a certeza de que rasguei aquele artigo.

Este é só um dos numerosos exemplos de intimidação empresarial a influenciar e a determinar programas de investigação. Outros que eu poderia citar encontram-se em praticamente todas as áreas de investigação: da física nuclear à saúde pública e às ciências sociais. No campo da biotecnologia, por exemplo, o financiamento das empresas está frequentemente ligado ao direito ao primeiro olhar sobre os resultados da investigação e a retardar a publicação até serem estudadas as possibilidades de patentes. Como disse recentemente um investigador de um projecto apoiado pela Hoescht, naquele laboratório todos são essencialmente servos contratados da Hoescht. (H. Hobbelink, 1991: 39) Outro investigador, referindo-se a um programa de biotecnologia na Universidade de Washington financiado pela Monsanto, disse publicamente: Não se pode levar a cabo nenhuma investigação sem a autorização da empresa.

- Em segundo lugar, e mais subtilmente, os subsidios empresariais permitem às companhias controlar mais do que simples projectos individuais: eles desempenham um papel essencial na determinação do quadro de referência mais vasto para a investigação.

Embora os subsídios directos das empresas às universidades e aos institutos de investigação constituam geralmente apenas uma pequena parte dos orçamentos totais da investigação (vindo do governo a grande maioria dos fundos), os subsídios de empresas são uma importante fonte de poder dentro dos departamentos de investigação, especialmente se houver pouco dinheiro de outras fontes. $\mathrm{O}$ financiamento empresarial traz segurança financeira a um projecto, conferindo-lhe uma «importância» que ele poderia de outra forma não merecer e reforçando o estatuto do investigador dentro do departamento. Por uma lógica perversa, a capacidade de «angariar» fundos empresariais torna-se uma via para a promoção - com o resultado de que muitos postos administrativos importantes nas universidades e institutos de investigação passaram a ser dominados por aqueles que partilham as prioridades das empresas. 
De facto, como os financiamentos empresariais habilitam os investigadores a obter subsídios correspondentes dos governos, mesmo os financiamentos empresariais de pequeno montante têm um efeito desproporcionado na orientação geral da investigação pública. Mediante a atribuição estratégica de subsídios à investigação, as empresas conseguem, efectivamente, orientar fundos públicos para a investigação que melhor serve os seus interesses. Com as próprias universidades a comportar-se hoje cada vez mais como empresas, também elas estão a começar a impulsionar os programas de investigação numa direcção que tenha em vista a rentabilidade. Na agricultura, por exemplo, a investigação em biotecnologia está a ser financiada na esperança de que dê origem a processos patenteáveis e a produtos que venham a fazer parte das futuras fontes de rendimento das universidades. Entretanto, o trabalho de investigação na agricultura orgânica, que poderia trazer benefícios sociais e ambientais mais claros, está a ser descurado ou eliminado.

- Em relação próxima com as anteriores temos uma terceira razão por que o financiamento empresarial da investigação produz rendimentos políticos tão altos para as empresas: o estabelecimento de ligações.

Quando as empresas de uma área, como a indústria agro-química, conseguem dominar tanto a investigação como a formação, actuam num ambiente que tem uma disposição geral favorável aos seus objectivos e perspectivas. Com uma cultura e uma visão comuns, as pessoas formadas ou empregadas no seio deste consenso geral podem mover-se livremente entre o sector académico, o sector público e o próprio governo. $\mathrm{O}$ resultado é uma relação de extrema proximidade entre as empresas e os seus supostos reguladores.

Esta relação de porta-giratória entre a indústria e a comunidade agrícola e académica mais geral é especialmente visível na constituição das comissões que decidem as políticas. Na Holanda, no início dos anos 90 , por exemplo, mais de um terço dos lugares na comissão que decidia sobre o financiamento à investigação em biotecnologia tinham sido atribuídos a empresas comerciais, com mais de metade destes sob controlo das quatro multinacionais mais importantes (T. Clunies-Ross e N. Hildyard, 1991).

Cultivando cuidadosamente os contactos pessoais - que começam com um pequeno subsídio de investigação e culminam num lugar público - , que são intensificados pela pertença às mesmas organizações profissionais e por amizades de interesse mútuo, os interesses empresariais conseguem maximizar as hipóteses de que a sua voz seja ouvida - e 
atendida - pelo governo. E é esse o lucro do financiamento da investigação, mesmo de investigação supostamente aplicada.

- E, em quarto lugar, numa era de patentes, o financiamento da investigação é uma via para garantir o controlo monopolista sobre certos tipos de produtos - e portanto sobre os mercados.

Vejamos o contrato de investigação que a Monsanto assinou com a Washington University em St. Louis (EUA), que está a investigar o uso medicinal de plantas pela tribo dos Aguaruna no Peru. Nos termos do contrato, a Monsanto está autorizada a testar, patentear e comercializar produtos derivados das amostras de plantas obtidas pela universidade. Em troca, a Monsanto "compensa» os Aguaruna e aceita pagar ao Peru uma percentagem sobre as vendas dos produtos. O Peru, entretanto, proporciona, e citamos, a certeza legal de que a Monsanto tem o direito de patente sobre quaisquer substâncias descobertas nos termos deste contrato. (Monsanto, 1998)

A Monsanto e outras empresas argumentam que essas patentes são necessárias para recuperar os custos da investigação. Na realidade, como admitem abertamente membros mais cândidos da indústria biotecnológica, o que as patentes significam é o estabelecimento de direitos de monopólio sobre mercados e áreas de investigação. Gordon Wright, do grupo francês de produtos de saúde e beleza Sanofi, é muito cândido: Defender-nos das empresas inovadoras é a parte mais dificil do trabalho. (G. Wright, 1997) Ele compara o registo de patentes ao alpinismo: se o objectivo é ser o primeiro a chegar ao cimo de uma montanha de 3000 metros, constitui uma vantagem garantir que mais ninguém possa escalar montanha alguma na zona. Assim, enquanto um pequeno grupo de investigadores e cientistas se instala na atmosfera rarefeita do campo três do Everest, o sistema legal tenta impedir outros de chegar sequer aos primeiros declives da montanha. As patentes são um dos instrumentos principais que as empresas têm usado até hoje para o fazer.

O financiamento da investigação científica é, portanto, uma das ferramentas principais da indústria para construir a infra-estrutura política necessária à sua actuação. Usa-a para proteger mercados. Usa-a para instrumentalizar os seus programas. Usa-a — juntamente com relações públicas e sondagens - para criar uma opinião pública aberta aos seus interesses (Lohmann, L., 1998). E usa-a para construir redes de administradores e burocratas favoráveis aos seus interesses.

Isto não deveria surpreender-nos. Por mais economicamente poderosa que seja uma empresa, o seu presidente do conselho de administração e 
os seus responsáveis pelo planeamento sabem muito bem que, para actuar eficazmente aos níveis nacional e internacional, têm de capturar o contexto local, pois perder o contexto local é ficar de fora. É ficar sem aliados que possam dominar e manipular por dentro padrões locais de controlo de forma favorável aos interesses transnacionais. Eles precisam de descer cá abaixo, da sala da administração até ao nível da exploração agrícola, da casa familiar e, sim, do laboratório, para construir as alianças tácitas, as relações patrão-cliente e as amizades íntimas que lhes permitem actuar.

Deverá isto preocupar-nos? Na minha opinião, sim, deve preocupar-nos muito. Quem controla a investigação - e no interesse de quem afecta-nos a todos. E também de formas que não são óbvias.

A imagem do mundo que a ciência dá - um resultado directo da investigação que leva a cabo - afecta mais do que os produtos atraentes que podemos comprar.

A falta de investigação sobre os efeitos que os produtos químicos têm na capacidade reprodutiva dos homens, por exemplo, dá corpo à ideia de que a reprodução é só assunto de mulheres, com consequências importantes para a saúde das mulheres como grupo social.

$\mathrm{Ou}$, analogamente, o estrelato conferido ao projecto do genoma humano dá corpo à ideia de que a essência da humanidade pode de alguma maneira ser capturada e reduzida a uma hipotética sequência de ADN, quando na realidade cada ser humano é diferente de todos os outros - e não existe (a não ser na imaginação científica) nada de parecido com o genoma humano.

Associada a um tal pensamento reducionista está uma atmosfera em que a opinião pública talvez não questione muito a ameaça daquilo que Ruth Hubbard e Elijah Ward chamaram a eugenia da normalidade - definindo-se normalidade por modelos genéticos arbitrários de seres humanos padrões e usando testes genéticos para eliminar os que não estão conformes (R. Hubbard e E. Ward, 1993).

A ciência é política. Nenhum cientista, por mais pura que a sua investigação pareça, pode escapar ao contexto político em que a ciência opera - ou ao seu poder político na determinação dos rumos públicos.

Mas os cientistas não têm de pôr-se humildemente de lado quando essas orientações são regressivas. E há muitos casos honrosos em que eles se recusaram a ficar de lado. Com o interesse público a ser cada vez mais secundarizado pelo poder crescente das empresas na determinação de programas de investigação, o meu apelo seria para os cientistas levarem este desafio a sério e se empenharem activamente em tornar a investigação mais responsável perante o público, em denunciar orientações regressivas e em fazer pressão por uma ciência que sirva o interesse público, por oposição a interesses de elite. 


\section{Referências}

R. van Den Bosch (1980), The Pesticide Conspiracy, Dorchester, Prism Press.

T. Clunies-Ross e N. Hildyard (1991), The Politics of Industrial Agriculture, Londres, Earthscan.

Gay, J. e Cole, M. (1967), The New Mathematics and Old Culture, Nova Iorque, Holt, Rhinehart and Winston.

S. Harding (1991), Whose Science? Whose Knowledge? Thinking from Women's Lives, Open University Press, Milton Keynes.

H. Hobbelink, H. (1991), Biotechnology and the Future of World Agriculture, Londres, Zed Books.

R. Hubbard; E. Ward (1993), Exploding the Gene Myth, Beacon Press.

J. Lave (1996), «The Savagery of the Domestic Mind», in Nader, L., Naked

Science: Anthropological Inquiries into the Boundaries of Power and Knowledge, Londres Routledge.

Lohmann, L. (1998), Whose Voice is Speaking? How opinion polling and cost-benefit analysis synthesize new 'Publics', Corner House Briefing 7, Sturminster Newton, <http://www.icaap.org/Cornerhouse/>.

Monsanto (1998), «Bioprospecting contract seeks fairness», in Monsanto, Report on Sustainable Development 1997, St. Louis, p. 28.

J. Richter (1996), Vaccination Against Pregnancy: Miracle or Menace?. Londres, Zed Books.

S. Sexton (1993), «The Reproductive Hazards of Industrial Chemicals: The Politics of Protection», in The Ecologist, Vol. 23, n. 6.

G. Wright (1997), Is there a future for pharmaceutical patents in the 21st century?, Palestra de abertura na EuroForum Conference, «Patent Protection for the Pharmaceutical and Biotech Industries», Londres, 20 de Novembro. 
(Página deixada propositadamente em branco) 
 \\ A palavra "fronteiras" pode ser tomada em} diferentes sentidos. Pode referir-se aos limites, necessariamente provisórios, entre o conhecido e o desconhecido, ou aos limites entre o possivel e o impossivel, e, dentro do possivel, entre o desejável e 0 indesejável. Fronteiras podem também ser as delimitações, nem sempre nítidas, entre ciência e não-ciência, e dentro da ciência, entre as várias disciplinas. Quais são então as fronteiras da ciência?

Neste livro, a resposta a esta pergunta é dada, segundo as mais diferentes perspectivas, por um conjunto notável de personalidades, cientistas ou não, entre as quais se contam três Prémios Nobel.

Rui Fausto, Carlos fiolhais e JoÃo Fillipe Queiró são, respectivamente, professores de Química, Física e Matemática na Faculdade de Ciências e Tecnologia da Universidade de Coimbra. 